\title{
A perspective of the epidemiology of malaria and anaemia and their impact on maternal and perinatal outcomes in Sudan
}

\author{
Ishag Adam ${ }^{1}$, Elhassan M. Elhassan ${ }^{1}$, Abd Elrahium D. Haggaz ${ }^{2}$, Abdel Aziem A. Ali ${ }^{3}$, Gamal K. Adam ${ }^{4}$ \\ ${ }^{1}$ Faculty of Medicine, University of Khartoum, Sudan \\ ${ }^{2}$ University of Geizera, Wad Medani, Sudan \\ ${ }^{3}$ Faculty of Medicine, Kassala University, Sudan \\ ${ }^{4}$ Faculty of Medicine, Gadarif University, Sudan
}

\begin{abstract}
Introduction: Both malaria and anaemia have adverse effects on maternal and perinatal outcomes. Thus there is an urgent need to investigate the co-epidemiology of malaria and anaemia and their combined impact on maternal and perinatal outcomes in the different regions of Sudan Methodology: Various cross-sectional and case control studies conducted during the years 2003-2010 to investigate the epidemiology of malaria and anaemia and their impact on maternal and perinatal outcomes in different regions of Sudan were compared.

Results: While $13.7 \%$ of antenatal attendants in New Halfa had peripheral microscopically detected Plasmodium falciparum malaria, placental malaria (using histological examinations) was prevalent in 32.0-40\% and $19.5 \%$ of parturient women in New Halfa and Gadarif Hospitals, respectively. Malaria was a risk factor for anaemia in New Halfa and for stillbirths in Omdurman Maternity Hospital. Anaemia was present in 52.5\%, 62.6\% and 80.2\% of pregnant women in Medani, New Halfa, and Gadarif Hospitals, respectively. In Gadarif, 57.3\% of pregnant women had a folate deficiency, while $1 \%$ had a vitamin B12, deficiency. In Medani, zinc and copper deficiencies were detected in $45.0 \%$ and $4 \%$ of pregnant women, respectively. Anaemia was a risk factor for low birth weight in Al-Fashir, for fetal anaemia in New Halfa, and for stillbirth in Kassala Hospital.

Conclusion: More care should be taken to ensure proper nutrition and malaria prevention such as bed nets and intermittent preventive treatments to avoid these diseases and their effects on maternal and perinatal outcomes.
\end{abstract}

Key words: malaria; anaemia; pregnancy; perinatal; Sudan

J Infect Dev Ctries 2011; 5(2):083-087.

(Received 10 June 2010 - Accepted 07 October 2010)

Copyright (C) 2011 Adam et al. This is an open-access article distributed under the Creative Commons Attribution License, which permits unrestricted use, distribution, and reproduction in any medium, provided the original work is properly cited.

\section{Introduction}

Malaria in pregnancy is a major public health problem in tropical and subtropical regions of the world and makes a significant contribution to maternal and perinatal morbidity and mortality [1,2]. Each year more than 500,000 women die during pregnancy or childbirth [1] and more than four million babies die in the first 28 days of life, accounting for $38 \%$ of mortality in children five years of age or under worldwide [3,4]. Maternal malaria infection is estimated to account for three to eight percent of all infant deaths [5].

Several studies have reported malaria as the primary reason for anaemia in pregnant women in other countries with unstable or stable malaria transmission [6,7]. Anaemia during pregnancy is associated with increased maternal morbidity and mortality [8]. The control of anaemia in women of reproductive age is one of the Safe Motherhood
Initiatives [9]. In Sudan, the largest country in Africa, malaria with unstable transmission dominates most parts including the eastern and central areas [10]. High rates of maternal and perinatal mortality have been observed in the different regions of Sudan; both malaria and anaemia were the major causes of these high levels of mortality [11-13].

Understanding the epidemiology of malaria and anaemia during pregnancy is important for deciding the control strategies. Studies investigating these parameters are thus vital and may be of great interest in providing health planners and caregivers with fundamental guidelines for the implementation of preventive measures. Therefore, the aim of this work was to determine the epidemiology of malaria and anaemia among pregnant women in different regions of Sudan by comparing the data from various individual studies [14-22]. 


\section{Methodology}

During the years 2003-2010, various crosssectional and case control studies [14-22] have been conducted to investigate the epidemiology of malaria and anaemia among pregnant women and to investigate the effect of malaria and anaemia on maternal and perinatal outcomes in the different regions of Sudan (Figure 1). These studies were designed to answer the desired research questions as applicable (e.g., cross-sectional studies for prevalence and risk factors). Likewise, different statistical methods were used to analyze the data as applicable per study. Each study indicated that both

Figure 1: Map showing hospital locations in different regions

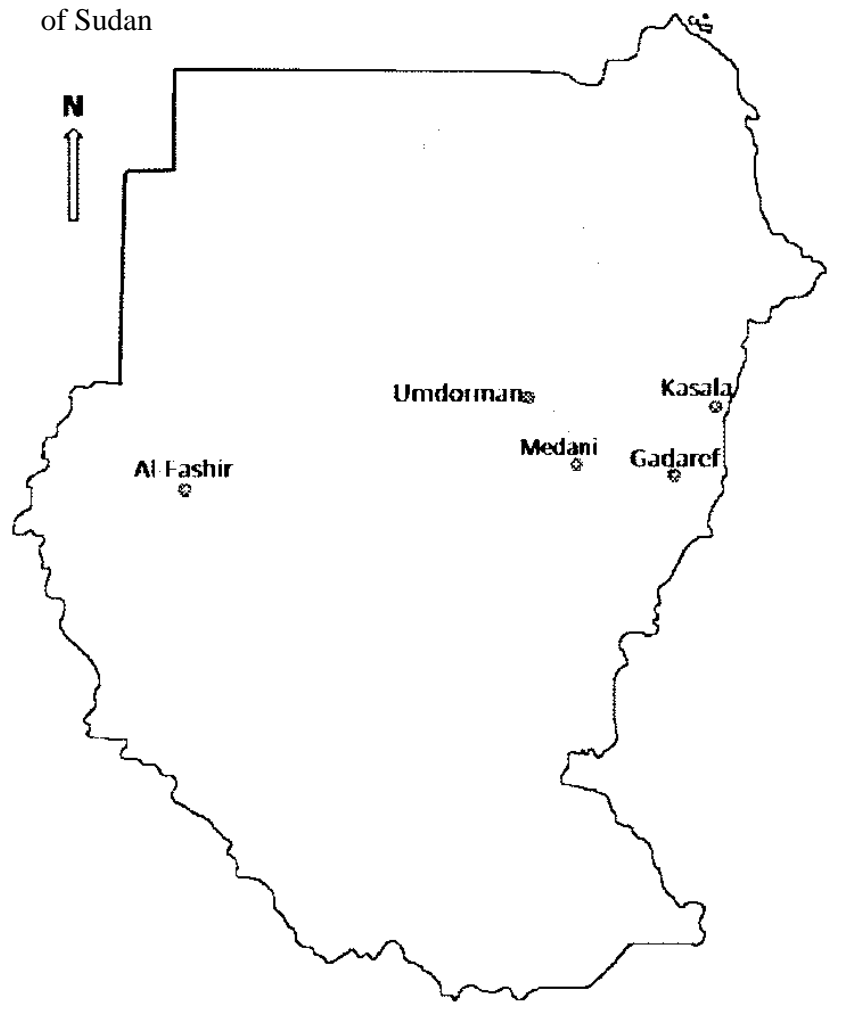

informed patient consent and ethical clearance from the different institutes in Sudan was obtained. The studies were analyzed individually and then compared. The data were not pooled.

\section{Results}

Prevalence of maternal malaria in Eastern Sudan
Cross-sectional studies were used to investigate the prevalence of malaria in pregnancy in Eastern Sudan. While $13.7 \%$ (102/744) of prenatal attendants

Table 1. Epidemiology of malaria during pregnancy in Sudan

\begin{tabular}{llll} 
Region & Prevalence & Risk factors & Reference \\
\hline New Halfa & $\begin{array}{l}13.7 \% \\
(102 / 744)\end{array}$ & & $\begin{array}{l}\text { Adam } \text { et al. } \\
{[14]}\end{array}$ \\
& & & Adam et al. \\
New Halfa & $40 \%(57 / 142)$ & & {$[15]$} \\
& & & Adam et al. \\
New Halfa & $\begin{array}{l}32.0 \% \\
(94 / 293)\end{array}$ & O & {$[16]$} \\
& $19.5 \%$ & Lack of & Adam et al. \\
Gadarif & $(46 / 236)$ & antenatal care & {$[17]$}
\end{tabular}

in New Halfa Teaching Hospital had peripheral microscopically detected Plasmodium falciparum malaria (diagnosed using blood films), placental malaria (diagnosed using placental histopathology) was prevalent in 32.0\% (94/293) and 19.5\% (46/236) of parturient women in New Halfa Teaching and Gadarif Hospitals, respectively (Table 1). In one other study at the New Halfa Teaching Hospital, $40 \%$ (57/142) of pregnant women were positive for malaria either by blood smear microscopy (17/142; $12 \%$ ) or using $\mathrm{P}$. falciparum-specific polymerase chain reaction (PCR) on peripheral blood specimens $(40 / 142 ; 28 \%)$ [15]. That is, $32 \%(40 / 125)$ of the smear-negative pregnant women were found to have submicroscopic malaria.

\section{Risk factors for maternal malaria}

In all these studies [14-17], neither age nor parity was a risk factor for malaria in these settings. In New Halfa Teaching Hospital, mothers with blood group $\mathrm{O}$ were at higher risk for placental malaria.

Epidemiology of maternal anaemia in the different regions of Sudan

Likewise, cross-sectional studies were used to investigate epidemiology of anaemia in these settings. Anaemia was present in 52.5\% (104/200), $62.6 \%$ (466/744) and 80.2\% (224/279) of pregnant women in Medani, New Halfa, and Gadarif Hospitals, respectively. In Gadarif, 57.3\% (160/279) of pregnant women had a folate deficiency and $1 \%$ 
had a vitamin B12 deficiency. In Medani, zinc and copper deficiencies were present in $45 \%$ (90/200) and $4 \%(8 / 200)$ of pregnant women, respectively (Tables $2,3)$.

Table 2. Epidemiology of anaemia during pregnancy in Sudan

\begin{tabular}{llll}
\hline Region & Elements & $\begin{array}{l}\text { Deficiency/Preval } \\
\text { ence }\end{array}$ & Reference \\
\hline Gadarif & Iron & $11.1 \%(31 / 279)$ & \\
& Folic acid & $57.7 \%(161 / 279)$ & $\begin{array}{l}\text { Abdelrahim } \\
\text { et al. }[19]\end{array}$ \\
& $\mathrm{B}_{12}$ & $1.0 \%(3 / 279)$ & \\
Kassala & Iron & $14.8 \%(37 / 205)$ & \\
& Zinc & $38 \%(95 / 250)$ & Ali et al. $[20]$ \\
Medani & Iron & $6.5 \%(13 / 200)$ & \\
& Zinc & $45 \%(90 / 200)$ & Bushra et al. \\
& Copper & $4.0 \%(8 / 200)$ & \\
\hline
\end{tabular}

\section{Risk factors for anaemia}

Malaria and pica (eating mud) were risk factors for anaemia in New Halfa and for stillbirth in Omdurman Maternity Hospital [18,23]. Age was not a risk factor for anaemia in all these studies. With the exception of one recent study conducted in Kassala, parity was not a risk factor for anaemia in all other studies.

\section{The effect of anaemia on perinatal outcomes}

Anaemia was a risk factor for low birth weight in Al-Fashir, for fetal anaemia in New Halfa, and for stillbirth in Kassala Hospital [24,25].

\section{Discussion}

Previously, high rates of maternal and perinatal mortality in the different regions of Sudan were observed [11-13], although malaria and its related anaemia were not included in these high rates of maternal and perinatal mortality. The main finding of the current analyses of previous studies was that there is a high prevalence of malaria and anaemia among pregnant women in the different regions of Sudan. Malaria and anaemia were furthermore observed to be predictors for poor perinatal outcomes. As in previous studies, anaemia was reported as a risk factor for fetal anaemia and low birth weight [22,24]. Several studies have reported malaria as a primary reason for anaemia in pregnant women in other countries [6,7]. Maternal anaemia and malaria have

Table 3. Micronutrients and trace elements deficiencies during pregnancy in Sudan

\begin{tabular}{llll}
\hline Region & Prevalence & Risk factors & Reference \\
\hline New Halfa & $\begin{array}{l}62.6 \% \\
(466 / 744)\end{array}$ & Malaria, pica & $\begin{array}{l}\text { Adam } \text { et al. } \\
{[18]}\end{array}$ \\
Gadarif & $\begin{array}{l}80.2 \% \\
(224 / 279)\end{array}$ & & $\begin{array}{l}\text { Abdelrahim } \\
\text { et al. }[19]\end{array}$ \\
& $58.4 \%$ & Parity, zinc & $\begin{array}{l}\text { Mohamed } \text { et } \\
\text { al. } \text { [20] }\end{array}$ \\
Kassala & $(146 / 250)$ & & Bushra et al. \\
& $52.5 \%(104 / 20$ & Pica & [21 \\
Medani & $0)$ & & $\begin{array}{l}\text { Haggaz } \text { et al. } \\
{[22]}\end{array}$ \\
& $53.5 \%$ & & \\
\hline
\end{tabular}

been reported in areas of unstable malaria transmission in Thailand and in Ethiopia, as well as in areas with stable malaria transmission [26,27]. Regardless of the transmission level and prepregnancy level of malaria immunity, maternal anaemia remains the most frequent consequence of malaria during pregnancy [28].

After documenting the high prevalence of malaria and anaemia among pregnant women in Eastern Sudan, precautionary measures against malaria, such as bed nets and intermittent preventive treatments, were recommended. Interestingly, there was poor knowledge of malaria and perception toward its treatment among pregnant women, as well as among interviewed midwifes in the area [29]. Indeed, socio-demographic factors such as lack of education and prenatal care were reported to be related to infection with malaria and maternal and perinatal outcomes. For example, lack of prenatal care was observed as risk factor for placental malaria in Gadarif [17] and lack of education and prenatal care were risk factors for poor perinatal outcomes in Khartoum [30].

Although Sudan is the largest African country and has different cultures that might be influenced by ethnicity and other factors, malaria and anaemia have high prevalence and interactions with each other irrespective of culture or ethnicity, and pregnant 
women are at risk for malaria and anaemia regardless of their age and parity, with the exception of one study in Kassala. In other African countries with intense malaria transmission, primigravidae and secundigravidae were the risk factors for malaria and its associated anaemia [6,7]. It is expected that multigravidae with previous feto-maternal interactions due to malaria infection should portray an immunological picture of malaria different from that of primigravidae. This difference would be a result of both immune cell priming, especially against malaria parasites, and the development of antibodies against adhesion molecules responsible for placental sequestration of parasites [31].

Human immunodeficiency virus (HIV) infection has become more prevalent and must now be considered a possible etiologic factor for anaemia and among the causes of poor maternal and perinatal outcomes in sub-Saharan Africa [32]. Previously, we have shown that pregnant women in central Sudan had low HIV prevalence and that they were poor uptakes for HIV testing and counseling [33,34], which could explain the scarcity of data concerning HIV in Sudan. Other communicable diseases were reported to have poor maternal and perinatal outcomes in most regions of Sudan; for example, viral hepatitis in Khartoum and visceral leishmaniasis (kala-azar) in eastern Sudan [35,36].

A limitation of this study is that it reviewed previous hospital-based studies, which might not reflect the situation in the community. Larger focused studies on the impact of malaria and anemia in pregnancy in Sudan and associated risk factors are therefore needed.

In summary, there was high prevalence of anaemia and malaria in the different regions of Sudan. Preventive measures such as bed nets and intermittent preventive treatments should be employed to reduce these diseases and their impact on maternal and perinatal outcomes..

\section{Acknowledgements}

I.A. was supported by the University of Khartoum, Khartoum, Sudan.

\section{References}

1. World Health Organization (2004) Strategic Framework for Malaria Control during Pregnancy in the WHO Africa Region, Brazzaville: WHO Regional Office for Africa. AFR/MAL/04/01.

2. Tagbor H, Bruce J, Browne E, Greenwood B, Chandramohan D (2008) Malaria in pregnancy in an area of stable and intense transmission: is it asymptomatic? Trop Med Inter Health 13:1018-1021.

3. Lawn JE, Cousens S and Zupan J (2005) Four million neonatal deaths: when? Where? Why? Lancet 365: 891-900.

4. Adam T, Lim SS, Mehta S, Buhta ZA, Fogstad H, Mathai M, Zupan J, Darmstadt, G (2005) Cost effectiveness analysis of strategies for maternal and neonatal health in developing countries. Brit Med J 331: 1107-1110.

5. Steketee RW, Nahlen BL, Parise ME and Menendez C (2001) The burden of malaria in pregnancy in malariaendemic areas. Amer J Trop Med Hyg 64 (Suppl.1-2): 2835.

6. Bouyou-Akotet MK, Ionete-Collard DE, MabikaManfoumbi M, Kendjo E, Matsiegui PB, Mavoungou E, Kombila M (2003) Prevalence of Plasmodium falciparum infection in pregnant women in Gabon. Malar J 2: 18.

7. Ndyomugyenyi R, Magnussen P (1999) Anaemia in pregnancy: Plasmodium falciparum infection is an important cause in primigravidae in Homina district, western Uganda. Ann Trop Med Parasitol 93: 457-465.

8. World Health Organization (1990) The prevalence of anaemia in women: a tabulation of available information. Geneva: Maternal Health and Safe Motherhood Programme, World Health Organization p100.

9. World Health Organization (1989) Report of the African regional consultation on control of anaemia during pregnancy. Brazzaville: WHO Regional Office for Africa.

10. Al Gadal AA (1986) Malaria in the Sudan. In Buck AA, ed. Proceedings of the conference on malaria in Africa. Washington, DC: American Institute of Biological Sciences 156-159.

11. Elhassan EM, Mirghani OA, Adam I (2009) High maternal mortality and stillbirth in the Wad Medani Hospital, Central Sudan, 2003-2007. Trop Doct 39: 238-239.

12. Haggaz AD, Radi EA, Adam I (2008) High perinatal mortality in Darfur, Sudan. J Matern Fetal Neonatal Med 21: 277.

13. Haggaz AA, Radi EA, Adam I (2007) High maternal mortality in Darfur, Sudan. Int J Gynaecol Obstet 98: 252253.

14. Adam I, Khamis AH, Elbashir MI (2005) Prevalence and risk factors for Plasmodium falciparum malaria in pregnant women of eastern Sudan. Malar J 4:18.

15. Adam I, A-Elbasit IE, Salih I, Elbashir MI (2005) Submicroscopic Plasmodium falciparum infections during pregnancy, in an area of Sudan with a low intensity of malaria transmission. Ann Trop Med Parasitol 99: 339-344.

16. Adam I, Babiker S, Mohmmed AA, Salih MM, Prins MH, Zaki ZM (2007) ABO blood group system and placental malaria in an area of unstable malaria transmission in eastern Sudan. Malar J 6: 110.

17. Adam I, Adamt GK, Mohmmed AA, Salih MM, Ibrahuim SA, Ryan CA (2009) Placental malaria and lack of prenatal care in an area of unstable malaria transmission in eastern Sudan. J Parasitol 95: 751-752.

18. Adam I, Khamis AH, Elbashir MI (2005) Prevalence and risk factors for anaemia in pregnant women of eastern Sudan. Trans R Soc Trop Med Hyg 10: 739-743.

19. Abdelrahim II, Adam GK, Mohmmed AA, Salih MM, Ali NI, Elbashier MI, Adam I (2009) Anaemia, folate and vitamin B12 deficiency among pregnant women in an area of unstable malaria transmission in eastern Sudan. Trans R Soc Trop Med Hyg 103: 493-496. 
20. Mohamed AA, Ali AA, Ali NI, Abusalama EH, Elbashir MI, Adam I (2010) Zinc, parity, infection and severe anaemia among pregnant women in Kassala, eastern Sudan.

Biol Trace Elem Res 137:225-230.

21. Bushra M, Elhassan EM, Ali NI, Osman E, Bakheit KH, Adam I (2010) Anaemia, Zinc and copper deficiencies among pregnant women in central Sudan. Biol Trace Elem Res 137:255-2261.

22. Haggaz AD, Radi EA, Adam I (2010) Anaemia and low birthweight in western Sudan. Trans R Soc Trop Med Hyg 1043: 234-236.

23. Bader E, Alhaj AM, Hussan AA, Adam I (2010) Malaria and stillbirth in Omdurman Maternity Hospital, Sudan. Int J Gynaecol Obstet 109: 144-146.

24. Adam I, Babiker S, Mohmmed AA, Salih MM, Prins MH, Zaki ZM (2008) Low body mass index, anaemia and poor perinatal outcome in a rural hospital in eastern Sudan. J Trop Pediatr 54: 202-204.

25. Ali AA, Adam I (2011) Anaemia and stillbirth in Kassala hospital, eastern Sudan, J Trop Pediatr 57:62-64.

26. Nosten F, Ter Kuile FO, Maelankirri L, Decludt B, White NJ (1991) Malaria during pregnancy in an area of unstable endemicity. Trans R Soc Trop Med Hyg 85: 424-429.

27. Newman RD, Hailemariam A, Jimma D, Degefie A, Kebede D, Rietveld AC, Nahlen BL, Barnwell JW, Steketee RW, Parise ME (2003) Burden of malaria during pregnancy in areas of stable and unstable transmission in Ethiopia during a nonepidemic year. J Infect Dis 187: 1765-1772.

28. Menendez C (1995) Malaria during pregnancy: A priority area of malaria research and control. Parasitol Today11: 178-183.

29. Adam I, Omer EM, Salih A, Khamis AH, Malik EM (2008) Perceptions of the causes of malaria and of its complications, treatment and prevention among midwives and pregnant women of Eastern Sudan. J Public Health 13: 129-132.

30. Hassan AA, Abubaker MS, Radi EA, Adam I (2009) Education, prenatal care, and poor perinatal outcome in Khartoum, Sudan. Int J Gynaecol Obstet 105: 66-67.

31. O'Neil-Dunne I, Achur RN, Agbor-Enoh ST Valiyaveettil M, Naik R, Ockenhouse C, Zhou A, Megnekou R, Leke R, Taylor DW, Gowda DC (2001) Gravidity-dependent production of antibodies that inhibit binding of Plasmodium falciparum infected erythrocytes to placental chondroitin sulfate proteoglycans during pregnancy. Infect Immunity 69: 7487-7492.

32. Gibson RS, Abebe Y, Stabler S, Allen RH, Westcott JE, Stoecker BJ Krebs N, Hambidge KM (2008) Zinc, gravida, infection, and iron, but not vitamin B-12 or folate status, predict hemoglobin during pregnancy in Southern Ethiopia. J Nutr 138: 581-586.

33. Mahmoud MM, Nasr AM, Gassmelseed DE, Abdalelhafiz MA, Elsheikh MA, Adam I (2007) Knowledge and attitude toward HIV voluntary counseling and testing services among pregnant women attending an prenatal clinic in Sudan. J Med Virol 79: 469-473.

34. Gassmelseed DE, Nasr AM, Homeida SM, Elsheikh MA, Adam I (2006) Prevalence of HIV infection among pregnant women of the central Sudan. J Med Virol 78: 1269-1270.

35. Ahmed RE, Karsany MS, Adam I (2008) Brief report: acute viral hepatitis and poor maternal and perinatal outcomes in pregnant Sudanese women. J Med Virol 80: 1747-1748.
36. Adam GK, Abdulla MA, Ahmed AA, Adam I (2009) Maternal and perinatal outcomes of visceral leishmaniasis (kala-azar) treated with sodium stibogluconate in eastern Sudan. Int J Gynaecol Obstet 107: 208-210.

\section{Corresponding author}

Ishag Adam

Faculty of Medicine,

University of Khartoum,

Khartoum, Sudan

Email: ishagadam@hotmail.com

Conflict of interests: No conflict of interests is declared. 